\title{
Fabrication of a three-dimensional electrochemical paper-based device (3D-ePAD) for individual and simultaneous detection of ascorbic acid, dopamine and uric acid
}

\author{
Nongyao Nontawong ${ }^{1}$, Maliwan Amatatongchai ${ }^{1 *}$ Wanchai Wuepchaiyaphum ${ }^{1}$, Sanoe Chairam ${ }^{l}$, \\ Saichol Pimmongkol ${ }^{2}$, Sirirat Panich ${ }^{3}$, Suparb Tamuang ${ }^{1}$ and Purim Jarujamrus ${ }^{1}$ \\ ${ }^{1}$ Department of Chemistry and Center of Excellence for Innovation in Chemistry, Faculty of Science, \\ Ubon Ratchathani University, Ubon Ratchathani 34190, Thailand. \\ ${ }^{2}$ Department of Physics, Faculty of Science, Ubon Ratchathani University, Ubon Ratchathani 34190, \\ Thailand. \\ ${ }^{3}$ Faculty of Science and Technology, RMUTP, Bangkok 10800, Thailand. \\ *E-mail: maliwan.a@ubu.ac.th, amaliwan@gmail.com
}

doi: $10.20964 / 2018.07 .65$

Received: 23 March 2018 / Accepted: 15 May 2018 / Published: 5 June 2018

We report the development of a three-dimensional electrochemical paper-based analytical device (3DePAD) for the individual and simultaneous determination of ascorbic acid (AA), dopamine (DA) and uric acid (UA). The device was fabricated by alkyl ketene dimer (AKD)-inkjet printing of a circularly hydrophobic zone on filter paper for application of aqueous samples coupled with screen-printing of the electrodes on the paper which was folded underneath hydrophobic zone. A self-assembled threeelectrode system, comprising a graphite paste modified with $\mathrm{Fe}_{3} \mathrm{O}_{4} @ \mathrm{Au}-\mathrm{Cys} / \mathrm{PANI}$ was fabricated on the patterned paper by screen printed through the pre-designed transparent film slit. The three electrodes of $\mathrm{Fe}_{3} \mathrm{O}_{4} @ \mathrm{Au}-\mathrm{Cys} / \mathrm{PANI}$ modified graphite electrodes $\left(\mathrm{Fe}_{3} \mathrm{O}_{4} @ \mathrm{Au}-\mathrm{Cys} / \mathrm{PANI} / \mathrm{GFE}\right)$ on the layout paper were served as the working electrode, the reference electrode, and the counter electrode, respectively. Cyclic voltammetry $(\mathrm{CV})$ was used to study the electrochemical mechanism of AA, DA and UA. The results indicated that a high sensitivity towards AA, DA and UA was observed. Our results suggested that coating the working electrode with anionic surfactant, SDS (1 mM, pH 2), provides the distinguishable oxidation peak potential of AA and did not overlap with the oxidation peak of DA and UA. As a result, simultaneous determination of these three molecules in a mixture can be achieved. Examples of individual quantification of DA and UA in pharmaceutical and urine samples were demonstrated using differential pulse voltammetry (DPV). Under the optimum condition, the developed 3D-ePAD gave a linearity ranged from 20 to $1,000 \mu \mathrm{M}$ for both DA and UA. The detection limits were 2.19 and $1.80 \mu \mathrm{M}$ for DA and UA, respectively. There are no significant matrix interferences in the analyzed samples which can be concluded that the proposed method is suitable for the quantification of DA and UA with sufficient accuracy and precision. 
Keywords: Three-dimensional electrochemical paper-based device (3D-ePAD), Gold-coated magnetite $\left(\mathrm{Fe}_{3} \mathrm{O}_{4} @ \mathrm{Au}\right)$, Polyaniline (PANI), Ascorbic acid, Dopamine, Uric acid

\section{$\underline{\text { FULL TEXT }}$}

(C) 2018 The Authors. Published by ESG (www.electrochemsci.org). This article is an open access article distributed under the terms and conditions of the Creative Commons Attribution license (http://creativecommons.org/licenses/by/4.0/). 